\title{
PENGUKURAN TINGKAT KECEMASAN MAHASISWA DALAM MENGHADAPI SKRIPSI DENGAN PENDEKATAN FUZZY INFRENCE SYSTEM MAMDANI
}

\author{
Arif Susanto dan Imam Sunoto \\ Dosen Program Studi Teknik Informatika Universitas Indraprasta PGRI \\ Email: arif_susanto@yahoo.com ${ }^{1}$
}

\begin{abstract}
Conditions are less supportive of the event that is being experienced by a person, would cause an unpleasant feeling in that person. Feeling unpleasant and very disturbing soul and the mind can affect the meaning of students to events or issues that are being faced as the thesis work. Usually meaning that occurs almost always less subjective and can include public opinion because of the mind and heart are in an unstable state. Anxiety is an unpleasant feeling that is characterized by terms such as anxiety, concern and fear unexplained, experienced in different levels of the situation which is considered threatening. Anxiety is a feeling of fear and dread highly about something that will happen about the threats or actual difficulties vague and unrealistic that will arise in the future but it is not clear, and may endanger the welfare of a person. Anxiety can be both physically and psychologically. Measuring the level of anxiety in the face of thesis students can use fuzzy logic mamdani as a means of measurement. After calculation and experiment, the results of the determination didapatlah anxiety conditions faced by applying fuzzy mamdani with matlab. With the use of fuzzy logic levels of anxiety experienced can be identified quickly.

Keyword: Anxiety, fuzzy, thesis, students
\end{abstract}

\section{PENDAHULUAN}

Pendidikan merupakan dasar utama dalam mengembangkan sumber daya manusia guna adaptif menghadapi berbagai persoalan sosial yang ada di masyarakat. Pendidikan pada hakikatnya adalah suatu interaksi, hubungan timbal balik, serta sarana pendidikan yang memadai yang nantinya akan digunakan untuk memecahkan proses dua arah, antara pendidik dan anak didik. Fungsi pendidikan adalah mengembangkan apa saja yang dibutuhkan untuk menghadapi anak didik.

Remaja biasanya menyelesaikan pendidikan tingkat akhir pada usia 18 tahun. Setelah itu, sebagian akan mencari kerja dan sebagian lain akan melanjutkan ke perguruan tinggi dan mendapat sebutan mahasiswa. Mahasiswa diharapkan menjadi tulang punggung atau penerus guna menjadi tenaga profesional yang berkualitas untuk membangun bangsa dan negara.

Suatu keadaan yang mengancam keberadaan kehidupan seseorang, akan menimbulkan suatu perasaan yang tidak menyenangkan pada diri orang tersebut. Perasaan tidak menyenangkan dan sangat mengganggu jiwa dan pikiran ini dapat mempengaruhi proses pemaknaan seseorang terhadap peristiwa atau masalah yang sedang dihadapi. Biasanya pemaknaan yang terjadi hampir selalu subjektif dan kurang dapat mengikutkan pendapat umum karena pikiran dan hati sedang dalam keadaan tidak stabil. Kecemasan adalah perasaan tidak menyenangkan yang ditandai dengan istilah-istilah seperti kekhawatiran, keprihatinan dan rasa takut yang tidak jelas penyebabnya, yang dialami dalam tingkatan yang berbeda atas situasi yang dianggap mengancam. 


\section{Tinjauan Pustaka Kecemasan}

Kecemasan merupakan rasa khawatir dan takut yang tidak jelas sebabnya. Seseorang yang mengalami kecemasan seringkali tidak dapat menyebutkan penyebabnya dengan jelas. Inilah yang mengakibatkan seseorang mengalami kecemasan biasanya mempunyai pandangan subjektif terhadap perasaan dan peristiwa yang dialami. Kecemasan dapat bersifat fisik maupun psikis.

Gejala yang muncul secara fisik antara lain, tidur tidak nyenyak, nafsu makan hilang, kepala pusing, dan lainnya. Gejala yang bersifat psikis antara lain merasa takut, tidak bisa memusatkan perhatian, rendah diri, hilang kepercayaan diri, dan lainnya. Kecemasan pada mahasiswa ketika menghadapi skrispsi muncul karena adanya perasaan takut dan tidak percaya diri apakah mahasiswa mampu untuk mengerjakan skirpsi. Banyak mahasiswa yang merasa takut untuk berhadapan dengan dosen pembimbing karena munculnya perasaan ini, maka akan menghambat mahasiswa itu sendiri ketika harus mengkonsultasikan tugas skripsinya tersebut dan tentu saja akan semakin memperpanjang proses pengerjaan skripsi. Seseorang yang merasa cemas akan merasakan jantung berdebar-debar, mudah merasa lelah, sesak nafas, sakit pada bagian dada, pingsan, pusing/sakit kepala, takut pada sesuatu yang akan terjadi.

\section{Macam-macam Kecemasan}

\section{Kecemasan Normal}

Dalam arti tradisional, istilah kecemasan (anxiety) menunjuk pada keadaan emosi yang menentang atau tidak menyenangkan yang meliputi interpretasi subjektif dan "arousal" atau rangsang fisiologis. Kecemasan dikonseptualisasikan sebagai reaksi emosional yang umum dan nampaknya tidak berhubungan dengan keadaan atau stimulus tertentu. Terkadang istilah kecemasan "free floating" digunakan untuk menggambarkan respon yang umum ini muncul tanpa sebab yang jelas.

Pada kesempatan lain, kecemasan digambarkan sebagai state anxiety dan trait anxiety. State anxiety adalah reaksi emosi sementara yang timbul pada situasi tertentu, yang dirasakan sebagai suatu ancaman. Keadaan ini ditentukan oleh perasaan ketegangan yang subjektif. Trait anxiety menunjuk pada ciri atau sifat seseorang yang cukup stabil yang mengarahkan seseorang untuk menginterpretasikan suatu keadaan sebagai ancaman yang disebut "anxiety proneness" atau kecenderungan akan kecemasan. Orang tersebut cenderung untuk merasakan berbagai macam keadaan sebagai keadaan yang membahayakan atau mengancam, dan cenderung untuk menanggapi dengan reaksi kecemasan.

\section{Kecemasan Abnormal}

Pada umumnya, kecemasan dianggap sebagai hal yang abnormal jika terjadi dalam situasi yang dapat diatasi dengan sedikit kesulitan oleh kebanyakan orang. Perasaan cemas yang terus menerus dan tinggi intensitasnya akan sangat mempengaruhi fungsi individu, sosial, relasi dan fungsi sekolah/pekerjaan seharihari. Didalam hal ini kecemasan telah menjadi masalah perilaku. Gangguan kecemasan sangat lazim terjadi pada masyarakat baik anak-anak maupun orang dewasa. 


\section{METODOLOGI PENELITIAN}

Berdasarkan sifat masalahnya penelitian ini menggunakan metode kualitatif, dimana dalam pendekatannya mempertimbangkan suatu peristiwa yang mempunyai makna dan arti tertentu yang tidak bisa diungkap secara kuantitatif, atau dengan angka-angka. Metode kualitatif sebagai suatu metode penelitian yang menghasilkan data deskriptif berupa kata-kata tertulis atau lisan dari orang-orang dan perilaku yang dapat diamati.

Dalam metode kualitatif terdapat usaha untuk mengungkap maslah atau peristiwa sebagaimana adanya. Lebih lanjut, penelitian ini akan mengolah data-data yang sifatnya deskriptif. Data deskriptif ini memiliki berbagai macam bentuk, misalnya tanskripsi (data dari sumber-sumber referensial, hasil wawancara baik primer maupun sekunder, dan catatan lapangan hasil observasi), gambar-gambar, foto, rekaman hasil wawancara dan sebagainya.

Dalam penelitian ini yang menjadi subjek penelitian adalah mahasiswa Fakultas Teknik Matematika dan Ilmu Pengetahuan Alam program studi Teknik Informatika Universitas Indraprasta PGRI Jakarta, dengan ciri-ciri:

1. Tidak mengambil mata kuliah lain selain skripsi.

2. Sudah mendaftarkan/mengajukan proposal skripsi selama minimal 3 bulan.

3. Tidak memiliki pekerjaan sampingan/part time.

4. Belum menikah.

5. Memenuhi skor yang telah ditentukan dalam skala kecemasan

\section{Pengertian Sistem Pendukung Keputusan}

Menurut Marimin dan Nurul (2010) Sistem adalah suatu kesatuan usaha yang terdiri dari bagian-bagian yang berkaitan satu sama lain yang berusaha mencapai suatu tujuan dalam suatu lingkungan kompleks. Pengertian tersebut mencerminkan adanya beberapa bagian dan hubungan antara bagian, ini menunjukkan kompleksitas dari sistem yang meliputi kerja sama antara bagian yang independent satu sama lain. Selain itu dapat dilihat bahwa sistem berusaha mencapai tujuan. Pencapaian tujuan ini menyebabkan timbulnya dinamika, perubahan-perubahan yang terus-menerus perlu dikembangkan dan dikendalikan.

Menurut Efraim (2005) Sistem pendukung keputusan sebagai sekumpulan prosedur berbasis model untuk data pemrosesan dan penilaian guna membantu para manajer mengambil keputusan untuk sukses, sistem tersebut haruslah sederhana, cepat, mudah dikontrol, adaptif lengkap dengan isu-isu penting, dan mudah berkomunikasi.

\section{Pengertian Logika Fuzzy}

Menurut Sri Kusumadewi (2006) sebelum munculnya teori logika fuzzy (fuzzy logic) dikenal sebuah logika tegas (crisp logic) yang memiliki nilai benar dan salah secara tegas. Sebaliknya logika fuzzy adalah Suatu logika yang memiliki nilai kekaburan atau kesamaran (fuzzyness) antara benar dan salah. Dalam teori logika fuzzy suatu nilai bisa bernilai benar dan salah secara bersamaan. Namun berapa besar kebenaran dan kesalahan suatu nilai tergantung pada bobot keanggotaan yang dimilikinya. Orang yang belum mengenal logika fuzzy pasti akan mengira bahwa logika fuzzy adalah suatu yang amat rumit dan tidak menyenangkan. Namun, sekali orang mengenalnya, ia pasti akan sangat tertarik dan akan menjadi pendatang baru untuk ikut serta mempelajari logika fuzzy. Logika fuzzy dikatakan sebagai logika 
baru yang lama, sebab ilmu tentang logika fuzzy modern dan metodis baru ditemukan beberapa tahun yang lalu, padahal sebenarnya konsep tentang logika fuzzy itu sendiri sudah ada pada diri kita sejak lama. Logika fuzzy adalah suatu cara yang tepat untuk memetakan suatu ruang input ke dalam suatu ruang output.

\section{Metode Mamdani}

Metode mamdani sering juga dikenal dengan nama Metode Max-Min. Metode ini diperkenalkan oleh Ebrahim Mamdani pada tahun 1975. Menurut Eng. Agus Naba (2009), Motivasi utama teori fuzzy logic adalah memetakan sebuah ruang input ke dalam ruang output dengan menggunakan IF-THEN Rule. Pemetaan dilakukan dalam suatu FIS, urutan rule bisa sembarang. FIS mengevaluasi semua rule secara simultan untuk menghasilkan kesimpulan. Oleh karenanya, semua rule harus didefinisikan lebih dahulu sebelum kita membangun sebuah FIS yang akan digunakan untuk menginterpretasikan semua rule tersebut. Mekanisme dalam FIS bisa dirangkum yaitu: FIS adalah sebuah metode yang menginterpretasikan hargaharga dalam vektor input, menarik kesimpulan berdasarkan sekumpulan IF-THEN rule yang diberikan, dan kemudian menghasilkan vektor output.

Menurut Kusumadewi (2006) untuk mendapatkan output, diperlukan 4 tahapan:

1. Pembentukan himpunan fuzzy. Menentukan variabel fuzzy dan himpunan fuzzinya. Kemudian tentukan derajat keanggotaan antara data masukan fuzzy dengan himpunan fuzzy yang telah didefenisikan untuk setiap variabel masukan sistem dari setiap aturan fuzzy.

2. Aplikasi fungsi implikasi pada metode mamdani. Fungsi implikasi yang digunakan adalah min. Hasil implikasi fuzzy dari setiap aturan ini kemudian digabungkan untuk menghasilkan keluaran infrensi fuzzy.

3. Komposisi Aturan (rule). Tidak seperti penalaran monoton, apabila sistem terdiri dari beberapa aturan, maka infrensi diperoleh dari kumpulan dan korelasi antar aturan. Ada 3 metode yang digunakan dalam melakukan inferensi sistem fuzzy, yaitu: max, additive dan Jumlah babilistik OR.

4. Penegasan (defuzzy). Defuzzifikasi adalah suatu himpunan fuzzy yang diperoleh dari komposisi aturan-aturan fuzzy, sedangkan output yang dihasilkan merupakan suatu bilangan pada domain himpunan fuzzy.

\section{HASIL DAN PEMBAHASAN \\ Hasil Penelitian}

Dalam penyusunan penerapan logika fuzzy mamdani untuk menentukan tingkat kecemasan mahasiswa dalam menghadapi skripsi terdapat beberapa langkah yang harus dilakukan untuk mendapatkan data yang valid dalam penyusunannya.

Setelah dilakukan perhitungan dan percobaan, maka didapatlah hasil penentuan kondisi kecemasan yang dihadapi dengan menerapkan metode fuzzy mamdani dengan matlab.

\section{PEMBAHASAN}

Ada 4 tahapan yang perlu dilakukan dalam penerapan logika fuzzy diantaranya: 


\section{Menentukan Himpunan Fuzzy}

a. Variabel Gejala Fisik

Variabel input Gejala Fisik meliputi ujung-ujung jari terasa dingin,pencernaan tidak teratur,detak jantung cepat, keringat bercucuran, tidur tidak nyenyak, nafsu makan hilang, kepala pusing, nafas sesak.

b. Variabel Gejala Psikis

Variabel input Gejala Psikis meliputi sangat takut, merasa akan ditimpa bahaya, tidak bisa memusatkan perhatian, tidak berdaya atau rendah diri, hilang kepercayaan pada diri, tidak tentram, ingin lari dari kenyataan.

Dari kondisi gejala-gejala di atas dapat dibentuk himpunan fuzzy seperti pada tabel di bawah ini.

Tabel 1. Pembentuk himpunan fuzzy

\begin{tabular}{|c|c|c|c|c|c|}
\hline \multirow[t]{2}{*}{ Fungsi } & \multirow[t]{2}{*}{ Nama Variabel } & \multirow[t]{2}{*}{ Range } & \multicolumn{3}{|c|}{$\begin{array}{c}\text { Nama Himpunan Fuzzy } \\
\text { (Domain) }\end{array}$} \\
\hline & & & Buruk & Cukup & Baik \\
\hline \multirow{9}{*}{ Input } & Gejala Fisik & $(0-10)$ & $(0-4)$ & $(3-7)$ & $(6-10)$ \\
\hline & Ujung-ujung jari terasa dingin & $(0-10)$ & $(0-4)$ & $(3-7)$ & $(6-10)$ \\
\hline & Pencernaan tidak teratur & $(0-10)$ & $(0-4)$ & $(3-7)$ & $(6-10)$ \\
\hline & Detak jantung cepat & $(0-10)$ & $(0-4)$ & $(3-7)$ & $(6-10)$ \\
\hline & Keringat bercucuran & $(0-10)$ & $(0-4)$ & $(3-7)$ & $(6-10)$ \\
\hline & Tidur tidak nyenyak & $(0-10)$ & $(0-4)$ & $(3-7)$ & $(6-10)$ \\
\hline & Nafsu makan hilang & $(0-10)$ & $(0-4)$ & $(3-7)$ & $(6-10)$ \\
\hline & Kepala pusing & $(0-10)$ & $(0-4)$ & $(3-7)$ & $(6-10)$ \\
\hline & Nafas sesak & $(0-10)$ & $(0-4)$ & $(3-7)$ & $(6-10)$ \\
\hline \multirow{8}{*}{ Input } & Gejala Psikis & $(0-10)$ & $(0-10)$ & $(0-4)$ & $(3-7)$ \\
\hline & Sangat takut & $(0-10)$ & $(0-4)$ & $(3-7)$ & $(6-10)$ \\
\hline & Merasa akan ditimpa bahaya & $(0-10)$ & $(0-4)$ & $(3-7)$ & $(6-10)$ \\
\hline & Tidak bisa memusatkan perhatian & $(0-10)$ & $(0-4)$ & $(3-7)$ & $(6-10)$ \\
\hline & Tidak berdaya atau rendah diri & $(0-10)$ & $(0-4)$ & $(3-7)$ & $(6-10)$ \\
\hline & Hilang kepercayaan pada diri & $(0-10)$ & $(0-4)$ & $(3-7)$ & $(6-10)$ \\
\hline & Tidak tentram & $(0-10)$ & $(0-4)$ & $(3-7)$ & $(6-10)$ \\
\hline & Ingin lari dari kenyataan & $(0-10)$ & $(0-4)$ & $(3-7)$ & $(6-10)$ \\
\hline Output & Kecemasan & $(0-10)$ & $(0-4)$ & $(3-7)$ & $(6-10)$ \\
\hline
\end{tabular}

\section{Fuzzifikasi}

Fungsi derajat keanggotaan yang digunakan adalah fungsi linier turun, fungsi segitiga dan fungsi linier naik.

Fungsi linier naik $\mu[\mathrm{x}]=\left\{\begin{array}{lr}0 ; & x \leq a \\ \frac{x-a}{b-a} ; & a \leq x \leq b \\ 1 ; & x \geq b\end{array}\right.$

Fungsi linier turun

$$
\mu[\mathrm{x}]=\left\{\begin{array}{lr}
\frac{b-x}{b-a} ; & a \leq x \leq b \\
0 ; & x \geq b
\end{array}\right.
$$

Fungsi segitiga

$$
\mu[\mathrm{x}]=\left\{\begin{array}{lr}
0 ; & x \leq \text { a atau } x \geq c \\
\frac{(x-a)}{(b-a)} ; & a \leq x \leq b \\
\frac{(b-x)}{(c-b)} ; & b \leq x \leq c
\end{array}\right.
$$




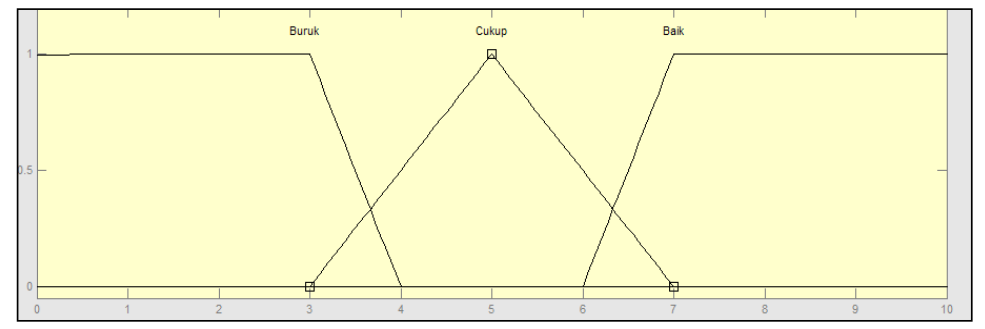

Gambar 1: Derajat Keanggotaan

\section{Pembentukan basis pengetahuan Fuzzy}

Tahap berikutnya membentuk basis pengetahuan yang berisi aturanaturan (rule) dalam bentuk IF...THEN yang disesuaikan dengan penelitian yang telah dilakukan.

\section{Aplikasi fungsi implikasi}

Fungsi ini digunakan untuk mendapatkan nilai $\alpha$-predikat hasil implikasi dengan cara memilih output himpunan fuzzy sesuai dengan derajat keanggotaan yang terkecil.

\section{Komposisi antar-rule}

Solusi himpunan fuzzy diperoleh dengan cara mengambil nilai maksimum aturan, kemudian menggunakannya untuk memodifikasi daerah fuzzy, dan mengaplikasikannya ke output dengan menggunakan operator OR (union).

\section{Defuzzyfikasi}

Input dari proses defuzzifikasi adalah suatu himpunan fuzzy yang diperoleh dari komposisi aturan-aturan fuzzy, sedangkan output yang dihasilkan merupakan suatu bilangan pada domain himpunan fuzzy tersebut. Sehingga jika diberikan suatu himpunan fuzzy dalam range tertentu, maka harus diambil suatu nilai crsip tertentu sebagai output. Dan metode yang digunakan adalah metode Centroid, dimana solusi crisp diperoleh dengan cara mengambil titik pusat $\left(\mathrm{z}^{*}\right)$ daerah fuzzy. Secara umum dirumuskan: $z^{*}=\int \mu(z) z d z \int \mu(z) d z$.

Batas nilai output dalam mengetahui tingkat kecemasan yang dialami mahasiswa dalam menghadapi skripsi adalah.

1) Tingkat kecemasan "BAIK" batas nilai output $<5$

2) Tingkat kecemasan "CUKUP" batas nilai output $<7,5$

3) Tingkat kecemasan "BURUK" batas nilai output $\geq 7,5$

\section{SIMPULAN DAN SARAN}

\section{Simpulan}

Berdasarkan hasil penelitian, maka dapat ditarik kesimpulan, yaitu.

1. Dengan penggunaan logika fuzzy, tingkat kecemasan mahasiswa dalam menghadapi skripsi dapat diketahui dengan cepat.

2. Pengukuran tingkat kecemasan mahasiswa dapat menggunakan Matlab R2009b, agar nantinya bisa didapatkan interface yang lebih interaktif. 
3. Penerapan logika fuzzy mamdani disini hanya sebatas pada pengukuran tingkat kecemasan mahasiswa dalam menghadapi skripsi tidak sampai pada pengambilan keputusan.

\section{Saran}

Berdasarkan simpulan di atas, maka peneliti mengajukan beberapa saran sebagai berikut:

1. Perlu adanya kesiapan sistem yang berjalan dengan baik. Hal ini dilakukan agar sistem dapat memberikan dukungan hasil yang terbaik.

2. Hasil penelitian ini perlu disosialisasikan kepada mahasiswa, sehingga dapat dicari solusi terbaik dari kondisi yang sedang dihadapi

3. Semoga penelitian ini dapat bermanfaat dalam penentuan tingkat kecemasan mahasiswa dalam menghadapi skripsi, dibutuhkan masukan, saran, dan kritikan agar dapat memperbaiki dan mengembangkan penelitian ini agar lebih baik.

\section{DAFTAR PUSTAKA}

Efraim Turban, Jay E. Aronson, Ting-Peng Liang. 2005. Decision Support System And Intelligent System-7th Ed. Pearson Education, New Jersey : Inc. Upper Saddle River.

Eng. Agus Naba. 2009. Belajar Cepat Fuzzy Logic menggunakan Matlab. Yogyakarta: Andi Offset.

Kusumadewi, Sri, Sri Hartati, Agus Harjoko, Retantyo Wardoyo. 2006. Fuzzy Multi-Attribute Decision Making (Fuzzy MADM). Yogjakarta: Graha Ilmu.

Marimin, Nurul, 2010, Aplikasi Teknik Pengambilan Keputusan dalam Manajemen Rantai Pasok, IPB Press, Bogor. 